\title{
Attachment dimensions as a predictor of emotional intelligence and sociability
}

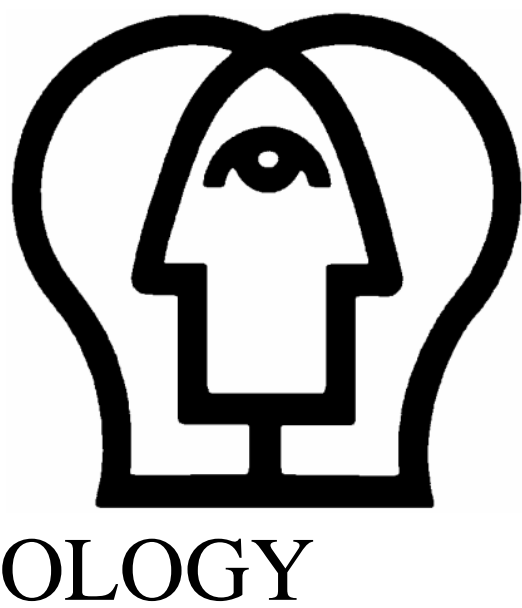

DEPARTMENT OF PSYCHOLOGY 


\section{ATTACHMENT DIMENSIONS AS A PREDICTOR OF EMOTIONAL INTELLIGENCE AND SOCIABILITY}

\section{Helen Svensson}

One of the ways in which the attachment relationships we develop during infancy influence us throughout life is by emotion regulation. Although studies have shown that attachment orientations affect emotional functioning, the effect of attachment dimensions on overall emotional functioning and sociability has still not been investigated. The purpose of the present study was to examine if attachment dimensions predict emotional intelligence (EI) and sociability. The sample consisted of 75 psychology students at Stockholm University who completed the Attachment Style Questionnaire (ASQ; Feeney, Noller \& Hanrahan, 1994) and a section of the Understanding Personal Potential (UPP; Sjöberg, 2001) that measures EI with selfreport as well as performance measures, and sociability. The current data did not offer conclusive evidence for the impact of attachment on EI, but suggests that secure attachment predicts sociability. The results are discussed in relation to existing theory and a more integrative approach is suggested for future studies.

As humans we find ourselves in constant interaction with the surroundings, we interact and we communicate. During infancy and childhood we develop mental models of relationships to others and these models affect us throughout life. The relationship to our caregivers, the attachment relationship, may be one of the most influential factors in developing a person's identity (Bowlby, 1973), next to factors as genetics, education, and peer socialization. The attachment relationship is the first of many that an individual depends upon for emotional security (Bowlby, 1973) and work on attachment theory has revealed individual differences in cognitive and affectional processes that are related to emotional abilities (e.g. Collins, 1996; Kobak \& Sceery, 1988). Even though everyone possesses emotions, individuals use and manage them in different ways in their everyday life. Emotional intelligence (EI) is a construct used to explain our ability to identify and deal with our emotions that has become very popular during the last twenty years. However, there are various definitions of the construct of EI, and the inconclusive nature is in part a result of the disagreement of whether it is an ability we possess or a personality trait, as well as whether to include social abilities in the construct or not (Bar-On, 1997; Goleman, 1998; Mayer, Salovey, \& Caruso, 2000). Despite the extensive research on EI during the last years, no research has been conducted on the relationship between attachment dimensions measured with the ASQ (Feeney, Noller \& Hanrahan, 1994) and EI. This might not only provide more information on the connection between attachment, emotional regulation and emotional abilities, but also provide a deeper understanding of the construct of EI.

\section{Attachment}

An attachment is an enduring affectional bond that unites two people. John Bowlby $(1969 / 1982)$ was the first to emphasize this bond between child and caregiver and suggest a model of its functioning. The attachment theory is based on the assumption that there is a behavioral system that is biologically founded in the human being. It is a 
universal function that affects everyone independent of differences as culture or genetics and Bowlby described the relationship between the child and caregiver as essential for the child's development and a source of understanding of continuity and change of human development (1969/1982; 1973). Bowlby studied young children's responses to separation in the hospitals during the decade following World War II. The behavioral system Bowlby discovered originated in observations of children's proximity to the caregiver during dangerous circumstances and how, when the caregiver was not available, fear behaviors like avoidance and attack were activated. According to the attachment theory, children with a secure attachment relationship to their caregivers view them as available and responsive to their needs, as well as a source of warmth and support in stressful situations. The emotional connection that develops between the caregiver and the child provides comfort, support and security and is therefore a crucial factor in order for the child to survive (Bowlby, 1969).

In contrast to the fear system that Bowlby discussed, Mary Ainsworth, another wellknown researcher in attachment theory, described an exploration system in the observation of children and caregivers (1967). In her research on infant-mother interaction conducted in Africa, Ainsworth noted that when the mother was present and available, the quality of the child's play increased and when the child became distressed, play and exploration rapidly reduced until the mother had comforted the child. Ainsworth consequently called the mother a "secure base" for exploration (1967).

Ainsworth and colleagues (Ainsworth, Blehar, Waters, \& Wall, 1978) developed the Strange Situation procedure, a method used to study the relationship between infant and caregiver in a laboratory setting. The mother and her child are placed in a room and allowed interaction when a stranger joins them. After a while the mother exits the room and leaves the child with the stranger. After a moment the mother returns, allowing the researchers to study the behavior of the child both when left alone with a stranger and when reunited with the mother. Based on these observations of infant-caregiver behavior a classification model was developed to capture individual differences in attachment style. Infants differ in how they use their caregivers as a base for comfort and contact, and three mutually exclusive attachment styles appeared, secure attachment, avoidant attachment, and anxious/ambivalent attachment. The majority of the children were securely attached, showing signs of missing the parent and upon reunion greeting them actively before returning to exploration. Securely attached infants seek comfort and contact with the caregiver. A minority of the infants were termed avoidant, overtly avoiding and ignoring the mother when she returned. A smaller minority was termed anxious/ambivalent attached. These infants showed anger toward the mother and often failed to explore after reunion. Children with anxious/ambivalent attachment demand contact but refuse to accept it when offered (Ainsworth et al., 1978).

Attachment theory has been considered a theory of emotion regulation (Cassidy, 1994; Kobak \& Sceery, 1988). The child's behavior is organized to maintain proximity to the caregiver because of its helplessness and dependency. When this goal is not fulfilled the child experiences anxiety. This primary affect regulation serves at promoting security by making the child stay near its caregiver (Bowlby, 1969/1982), and facilitating exploratory behavior using the caregiver as a safe base (Ainsworth et al., 1978). The relation between child and caregiver will become internalized in the child as working models and function as rules that orient the individual's emotional reaction to stressful 
situations (Kobak \& Sceery, 1988). According to Bretherton and Munholland (1999), the internal working model will work as a prototype for all future relationships, and serve as guidance for how the individual will experience, express, and manage distressing emotions. Internal working models, thus, are used as strategies to help regulate emotions, and orient behavior in our daily life (Bretherton \& Munholland, 1999). The child will, in the relationship with the attachment figure, develop representations and expectations of self and others, and individuals whose caregivers have shown loving and caring qualities are able to create working models of self as lovable, others as reliable and relationships as important (Bowlby, 1969/1982). Individuals who have a secure attachment pattern develop positive working models which allow them to manage emotional information in an effective way. Children that does not experience a consistent loving and secure connection with the caregivers develop defense mechanisms to manage the feelings of distress (Bretherton \& Munholland, 1999).

One premise of attachment theory is that these early experiences continue to influence individuals across the life span. The schemas have an effect on how relationships to others are formed and managed, and are said to be stable unless future experiences consistently conflict with the original scripts. Thompson (1999) has described the developmental multi-influential nature of attachment, with outcomes determined by many factors, making attachment continuity complex and multifaceted. Children seem to vary on to what extent attachment security remains over time, with studies showing both remarkable stability (Main \& Cassidy, 1988) and change (Zimmermann, FremmerBombik, Spangler, \& Grossman, 1997) in attachment between Strange Situation classifications and assessments years later. The complex patterns have been shown to be both real and meaningful based on external correlates with discontinuity, excluding measurement errors as a source of the inconsistent results. Based on these results, researchers have concluded that attachment experiences are important but can be altered by later experiences (e.g. Sroufe, Carlson, Levy, \& Egeland, 1999).

Even though research proposes that early experiences are of importance when it comes to adult attachment there are big differences in the cognitive and emotional composition of the child and adult. Categorization might be a useful way of describing and systemizing infant behavior, however, the affective-cognitive aspects of adult attachment require measures with further discriminative capacities. With measures that assess attachment dimensionally, forcing people into categories is evaded. Furthermore, using the entire variability of the scales makes it possible to see potential differences in attachment between people that would have been categorized to the same styles (Stein et al., 2002) and avoids the view of attachment style as a fixed entity.

The attachment measurement used in this study, the Attachment Style Questionnaire (ASQ; Feeney, Noller, \& Hanrahan, 1994), measures attachment with scores on five scales and provides the opportunity to assess attachment as dimensions, thus escape the categorical approach. The ASQ is theoretically inspired by Bartholomew's (1990; Bartholomew \& Horowitz, 1991) four-group model with one scale (confidence in self and others) reflecting secure attachment, and four scales (discomfort with closeness, relationships as secondary, need for approval and preoccupation with relationships) reflecting insecure attachment. The model combines the affective and cognitive aspects of attachment and can also be expressed as a combination of anxiety (self) and 
avoidance (other) (Griffin \& Bartholomew, 1994). The relationship styles individuals develop are, according to this model, based on positive and negative interpretations of self and others, and crossing the dimensions yields four outcomes, each representing an attachment style: (i) secure, positive image of self and others, comfortable with autonomy and intimacy, (ii) dismissing, positive self-image but negative image of others, rejects intimacy and prefers independency, (iii) preoccupied, negative self-image and positive image of others, preoccupied with relations, (iv) fearful, negative image of both self and others, high levels of internal pain and fear of intimacy and rejection (Bartholomew, 1990; Bartholomew \& Horowitz, 1991).

The research on attachment might be somewhat confusing with the use of different classifications where the preoccupied style also corresponds to Hazan and Shaver's (1987) anxious/ambivalent style whilst fearful and dismissing together form the avoidant style. This means research is usually conducted classifying people into either three groups (the tripartite model): secure, anxious/ambivalent, and avoidant (Hazan \& Shaver, 1987), or four groups: secure, preoccupied, dismissing(-avoidant), and fearful (-avoidant) (Bartholomew, 1990).

One of the scales of ASQ, confidence in self and others, reflects Bartholomew's (1991) secure attachment and measures attitudes towards self and others. People with high scores on this scale see others as approachable and responsive, they have a secure and trusting relation to self and others, and are able to form bonds and separate without too much anxiety (Feeney \& Noller, 1991). Discomfort with closeness reflects an attachment style where interpersonal relations are a source of anxiety. People with high scores on this scale protect themselves from the feeling of vulnerability by being distant and not attaching to others. Relationships as secondary reflect a style where independence from others is stressed, and personal achievements are seen as more important than interpersonal relations. People high in need for approval experience an anxious need to be liked and accepted by others. Individuals who are high in preoccupation with relationships experience anxiety in their relationships and, in particular, about possible abandonment and relationship loss (Feeney et al., 1994).

Feeney et al. (1994) conducted a factor analysis on the ASQ items and concluded that a five-dimensional model accounted for more variance than the three-factor model with the insecure styles of the tripartite model reflecting combinations of the insecure dimensions of the ASQ. The avoidant style was mainly reflected by discomfort with closeness and relationships as secondary, two scales that primarily measures attitudes towards others. The anxious/ambivalent style was reflected by need for approval and preoccupation with relationships, scales that primarily measures attitudes towards the self (Feeney et al., 1994). Hence, according to attachment theory people differ in how they see and judge themselves and each other, this affects the individual and influence how they will react to everyday situations, especially distressing ones. Differences between individuals in how they perceive and manage feelings of distress depend on how they perceive the situation in which emotions are created. This might be a result of how we got 'emotionally tuned' in the early attachment relationships.

\section{Emotions}

Emotions are a reaction towards something, a response to either an internal or external occurrence (Schachter, 1951). The emotions affect not only the individual herself but 
also the people in her surroundings, which explain its adaptive function in personal and social contexts. 'Emotions' and 'affect' are often used interdependently, but the term 'emotion' will generally be used here for the sake of consistency.

Charles Darwin discussed aspects of our behavior decided by genetics and the universal nature of emotions already in 1872, and showed great interest in the fact that young and old, humans as well as animals, expresses mental states with the same kind of expressions (Darwin, 1872). He claimed our expressions to be the first mean of communication between the mother and her child and being able to manage different emotions as crucial for survival (1872). The infant watches his/her cries and smiles empathetically reflected in the caregivers face and as he or she grows, learns to discriminate more finely among different types of emotions (Darwin, 1872). Research has shown that as neural capabilities develop, emotional responses to certain external stimuli also becomes more stable and that the interpersonal communicative power of emotions are of crucial importance to social adaptation and our attachment relationships (e.g. Fischer et al., 1990). According to Bowlby (1969/1982) our emotions have three primary functions; first, they help us evaluate signals both from our environment and from within, and guide us in how to behave. Second, they inform us about how we feel, and third, they are an important component in communication with others.

There is a wide range of different theories of emotion. Nonetheless, regarding normal adult functioning they have several important similarities; Fuendeling (1998) sums it up as "an innate, bio-socially determined process that guides adaptive behavior" (p. 296), interdependent with cognition but distinct from it. Both a physiological arousal or change component and a component of mental experience is said to be involved in emotions according to most emotional theorists, and the strong link between emotion and motivation is highlighted (Fuendeling, 1998).

As the child grows the emotional expression becomes increasingly under voluntary control. This depends on greater and more developed self-monitoring and cognitive abilities that interact with socialization (Fuendeling, 1998). With the ability to hold long-term plans and with the increased understanding of symbolic logic, control of emotions is developed with the main reasons thought to be to motivate pursuit of goals and conform to social expectations. The effect of parents' responses on the child's affective responses is described much in the same way as attachment theory, with the increased interdependence of affect and cognition agreed upon (Fuendeling, 1998).

\section{Emotional intelligence}

Emotional intelligence (EI) is one of the factors said to affect the quality of the interaction between individuals. EI refers to the extent to which individuals are able to identify their own feelings and the feelings of others, regulate them, and use the information provided to motivate adaptive behavior (Mayer, Salovey, \& Caruso, 2000).

There are three conventional definitions of EI, whereof two have found empirical support. Salovey and Mayer's (1990) model focuses on emotion-related abilities assessed through performance-based tests. According to Mayer and Salovey (1997), "Emotional intelligence involves the ability to perceive accurately, appraise, and express emotion; the ability to access and/ or generate feelings when they facilitate thought; the ability to understand emotion and emotional knowledge; and the ability to 
regulate emotions to promote emotional and intellectual growth" (p. 10). Furthermore, people with high EI are able to use emotional information in order to enhance cognitive activities and facilitate social functioning according to the theory (Mayer \& Salovey, 1997; Salovey \& Mayer, 1990).

Bar-On's (1997) emotional-social model account for EI as a personality trait that should be measured with self-reports instead of ability tests. According to Bar-On's model "emotional-social intelligence is a cross section of interrelated emotional and social competencies, skills and facilitators that determine how effectively we understand and express ourselves, understand others and relate with them, and cope with daily demands" (2006, p. 14).

In Goleman's mixed model (1995), EI is described as a competence including sociability and other non-cognitive abilities, and has been criticized for being too inclusive of abilities seen as positive, as well as for its lack of empirical findings. Other definitions of EI in the literature are Petrides and Furnham's (2000) definition of EI as appraisal and expression of emotions, regulation of emotions, and utilization of emotional information in thinking and acting. Emotional intelligence is defined in this study as the ability to identify and manage emotions within yourself and others (Sjöberg, 2001). As the variety of definitions illustrate, researchers have not yet reached a consensus on what should be included in the construct of EI.

Our knowledge of EI is only as good as our measures of it. One of the ambiguities of the EI construct is whether it is an ability we possess, or a personality trait. As a result, there are self-report measures and performance based measures to assess the construct, and the correlation between the two is usually positive but weak (Brackett, Rivers, Shiffman, Lerner, \& Salovey, 2006; Sjöberg, 2001). Some researchers mean that EI should be measured as ability because of its nature as a type of intelligence. They mean that this method gives the most theoretical satisfaction (Mayer \& Salovey, 1997). Performance based tests have also been criticized because of the subjective nature of emotions; they mean there is no such thing as a correct answer (Sjöberg, 2001). Both types of tests may still provide interesting information useful in various domains, in the sense of the "true" information (performance based EI) versus the most "useful" information (self-report EI) (Sjöberg, 2001).

Christiansen, Janovics, and Siers (2010) examined the validity of self-report and performance based measures and found that performance EI was more related to cognitive ability than personality, whereas self-reported EI was more related to personality than cognitive ability. Structural equation modeling suggested a two-factor model with separate factors for the two types of measures instead of a one-factor solution (Christiansen et al., 2010). Critics of the EI concept question not only the definition and measurement of EI but also whether EI has incremental validity beyond personality traits and cognitive ability, especially regarding job performance (Joseph \& Newman, 2010).

The influence of attachment on emotions

Both Bowlby and Ainsworth early stressed the strong influence of attachment on the full range of human emotions (Ainsworth et al., 1978). An individual's emotional skills begin with good child-parent interaction where the child learns to identify and label 
his/her emotions, and connect them to social situations (Mayer, \& Salovey, 1997). Thompson, Flood, and Lundqvist (1995) suggest that the relationship with early caregivers is of paramount importance to the child's development of emotion regulation. The authors define emotion regulation as "the process of initiating, maintaining, modulating, or changing the occurrence, intensity, or duration of internal feeling states and emotion-related physiological processes" (Thompson et al., 1995). Emotion regulation is often achieved through effortful management of attention and cognitions that affect the interpretation of the situation as well as through neurophysiological processes. Having an emotionally present caregiver during childhood brings opportunities for the child to learn emotions and successfully develop emotion regulation. Therefore, children with a secure attachment are more emotionally competent and are able to keep their behavior organized even though they find themselves in contexts of emotional arousal (Thompson et al., 1995).

Securely attached individuals possess positive emotional-regulative abilities (Cooper, Shaver, \& Collins, 1998) and adaptive patterns of emotional expressiveness (Thompson et al., 1995), while insecurely attached individuals have been shown to have more dysfunctional emotion regulation strategies (Brennan \& Shaver, 1995). Insecure attachment is associated with emotional defenses that inhibit information processing of emotional messages, and block awareness of feelings and intentions in self and other (Bowlby, 1969).

Adult attachment incorporates both affective and cognitive strategies that influence emotional reactions which means secure, anxious/ambivalent and avoidant persons use different strategies of affect regulation and emotion information processing (Shaver, Collins, \& Clark, 1996). Individuals with secure attachment use flexible and suitable strategies that minimize stress and emphasize positive emotions. These individuals are able to acknowledge distress and tolerate stressful events without being overwhelmed (Cooper et al., 1998). Anxious attachment has been related to hyper vigilance, emphasizing negative emotions and experiencing the situations as more stressful (Mikulincer et al., 1998), often with an emotional instability in social interaction (Simpson, 1990). Those with avoidant attachment tend to inhibit emotional experiences, keeping an emotional distance from others or avoid confrontation with stressful events (Hazan \& Shaver, 1987).

Furthermore, secure attachment has been associated with better perception, facilitation, understanding, and management of emotions (Peck, 2003; Zimmerman, 1999), as well as superior abilities to express emotions (Cassidy, 1994). Magai, Distel, and Liker (1995) studied the relation between adult attachment and emotion perception, and found that securely attached individuals were relatively accurate in decoding facial expressions of negative emotions, while avoidant persons had lower scores in emotion decoding accuracy (especially joy). Anxious/ambivalent males were inaccurate in decoding anger but females were more accurate, proposing gender as a moderator of the relationship (Magai et al., 1995).

In a study conducted on adolescents by Laible (2007) it was shown that having a secure relationship to parents and peers was positively correlated to being more emotionally aware, more sympathetic, more prosocial, and expressing more positive affect. 
Kafetsios (2004) investigated the relationship between attachment orientations, assessed with the relationship questionnaire (RQ; Bartholomew \& Horowitz, 1991), and emotional intelligence, measured as a set of abilities with the MSCEIT (Mayer, Salovey, \& Caruso, 2002). Results showed a positive relation between secure attachment and all subscales of the MSCEIT except perception of emotion, and total EI score. Preoccupied attachment was negatively associated with perception of emotions, but the relationships with fearful and dismissing attachment styles were not significant (Kafetsios, 2004).

Hamarta, Deniz, and Saltali (2009) studied if attachment measured with the RSQ (The Relationships Scales Questionnaire; Griffin \& Bartholomew, 1994) predicted EI as trait. EI was measured with Bar-On's EQ-I $(1997 ; 2006)$ and the results indicate a positive significant correlation between secure attachment and all subscales of EI. Attachment style had a significant effect, with secure and dismissing attachment styles significantly predicting, the subscale labeled interpersonal intelligence. Fearful attachment predicted the subscale stress management.

\section{Sociability}

Sociability is the tendency to seek the company of others, i.e. to be friendly, and is determined by both nature and nurture (Flanagan, 1999). Even though pretty much everybody shows signs of sociability, some are more sociable than others. Babies love interaction and infants that respond to the interaction is more likely to form emotional relationships. It is a survival mechanism for the infant to use these social abilities since babies that form bonds are more likely to be taken cared of (Flanagan, 1999). Several definitions of EI (e.g. Bar-On, 1997; Goleman, 1995) include various forms of sociability, highlighting the relation between emotional and social intelligence. Others think this is a too wide-ranging definition including most things that are seen as good and positive without theoretical or empirical support (Sjöberg, 2001). Sociability is measured with a self-report scale in this study, and is defined as the ability to establish and maintain close relationships, and solve social problems (Sjöberg, 2001).

Attachment security is an important foundation for a person's provision of high quality care to others. Securely attached people show a wide range of emotions which helps them react to situations with a high level of adaption and therefore tend to maintain and enhance relationship quality. On the other hand, insecurely attached individuals show a more narrow range of emotions, hence react to emotional events with defensive hyper activation or deactivation (Mikulincer \& Shaver, 2005).

Social competence has been associated with positive emotionality, indicating that individuals need to be able to process, manage, and express emotions correctly in order to understand and navigate the social world; there is an interaction between the two (Argyle \& Lu, 1990). Indicators of social adaptation, including more prosocial behavior among schoolchildren (Rubin, 1999), and greater empathy (Ciarrochi, Chan, \& Caputi, 2000), have been associated with higher scores on emotional intelligence tests. Lopes, Salovey, and Straus (2003) showed, in their study on college students, how scoring higher on managing emotions was associated with less conflict and antagonism in their relationship with a close friend, as well as more companionship, affection, and support in their relationship with a parent. 
Studies have shown a correlation between insecure attachment styles and experiencing problems in interpersonal relations. For example, securely attached people have been shown to better manage negative emotions in social interaction than insecurely attached individuals (Kobak \& Sceery, 1988), and provide additional positive emotions into these interactions (Simpson, 1990). Studies on romantic relationships have shown that secure people tend to highlight the importance of communication and expression, and perceive their partners as responsive to their signals (Collins \& Read, 1990). Persons with insecure attachments, on the other hand, have poorer interpersonal functioning in romantic relationships (e.g. Bookwala \& Zdaniuk, 1998; Collins \& Read, 1990), and are less likely to seek and receive emotional support from relationship partners when under stress (Simpson, Rholes, \& Nelligan, 1992).

A study conducted by Thompson and Lamb (1983) on attachment and stranger sociability in infancy showed that attachment relationships seem to be associated with sociability during the same age period but that the influence on later sociability is mixed. At both 12.5 months and 19.5 months of age, securely attached infants had the highest sociability scores. In addition, sociability scores at both ages were highly correlated when attachment status was consistent, but predictions with the security of attachment were not meaningful when attachment was inconsistent (Thompson \& Lamb, 1983).

No studies on the relationship between attachment and sociability in adulthood have been found, but securely attached individuals have been shown to be more socially skilled (DiTomasso, Brannen-McNulty, Ross, and Burgess, 2003). Kafetsios and Nezlek (2002) studied the relation between attachment styles and everyday social interaction and found that securely attached subjects had interactions that were more intimate and more emotionally optimistic. Persons with secure attachment also felt that others were more responsive to them and to their needs. Differences between attachment styles in social interaction were most pronounced between secure and dismissive avoidant subjects, and minimal between the secure and fearful types. In contrast, differences in reactions to interactions with 'close' and 'not close' friends were more pronounced for fearful types than for secure, dismissing, or preoccupied types (Kafetsios \& Nezlek, 2002).

\section{Present study}

Previous findings show that attachment styles seem to have an effect on EI and social interaction. Nevertheless, information about how the influence of attachment styles differ has gone missing in studies not distinguishing between the various types of insecure attachment. This may be one of the sources of the conflicting results since previous studies have shown that there are relevant emotional and cognitive differences between individuals in these groups. Using the five attachment dimensions for analyses makes it possible to further discriminate between the insecure groups. There seems to be an effect of attachment on emotions using the tripartite model (Collins, 1996; Magai et al., 1995), and on EI abilities (Kafetsios, 2004), trait EI (Hamarta et al., 2009) and social interaction (Kafetsios \& Nezlek, 2002) using the four-group model but the effect using the five ASQ dimensions (Feeney et al., 1994), has to my knowledge not been studied. Furthermore, although attachment orientations affect emotional functioning, more systematic investigations, where the overall emotional functioning is studied, are lacking. There is a need for a macroscopic approach, an integrative understanding. 


\section{Object of the study}

The object of the present study was to examine the impact of attachment dimensions on EI and sociability. On the basis of the literature review confidence in self and others is expected to correlate positively with performance EI, self-reported EI and with sociability. All of the dimensions that reflect insecure attachment are expected to correlate negatively with both types of EI and with sociability. Because of the lack of literature there are no hypotheses on the impact of each dimension more specifically.

Method

\section{Participants}

A total of 89 students in the Department of Psychology at Stockholm University, Sweden, participated in the study. Due to technical problems to register data, 14 individuals were excluded resulting in analyses conducted on 75 participants (59 female, 16 male). The participants ranged in age from 19 to 46 years with a mean age of $25.78(\mathrm{SD}=6.04)$.

\section{Measures}

$A S Q-S W E D$.

The Attachment Style Questionnaire (ASQ; Feeney, et al., 1994) is a self-report questionnaire aimed at measuring attachment style in adulthood (e.g., discomfort with closeness, I worry about people getting too close; relationships as secondary, Doing your best is more important than getting along with others; preoccupation with relationships, I wonder how I would cope without someone to love me; need for approval, I worry that I won't measure up with other people). The ASQ was translated into Swedish by Håkansson and Tengström (ASQ-SWED; 1997). This 40-items questionnaire asks participants to rate aspects of self and others on a Likert scale ranging from 1 (totally disagree) to 6 (totally agree). The items tap on relationships in general and not romantic or close relationships in specific. The internal consistency was acceptable, with a Cronbach's alpha ranging from .76 to .84 in the original version, and from .71 to .84 in the Swedish version (Feeney et al., 1994, Håkansson \& Tengström, 1997).

$U P P$.

Participants also completed the EI and sociability module of the Swedish test Understanding Personal Potential (UPP; Sjöberg, 2008). The UPP was developed to assess personality in adults, with an orientation towards working life. The EI module of the UPP includes measures of trait EI with a self-report questionnaire as well as ability EI with a performance test.

Self-report EI is measured with a 15 item questionnaire (e.g., I can rarely predict how I will react emotionally), and sociability with an 8 item questionnaire (e.g., Other people's behavior is easy to understand). Items from the two questionnaires were randomly mixed and participants were asked to indicate to what extent the statement describes them on a Likert scale ranging from 1 (totally disagree) to 5 (totally agree). Reliability measures have shown acceptable internal consistency, Chronbach's alpha for self-report EI and performance EI was .75, and .78 on the sociability scale. To delete the 
impact of impression management and obtain higher quality of data, an overt scale was used (See Sjöberg, 2009 for a description).

Performance EI is measured by participants making judgments of emotions expressed in four different photographs of a face. Participants judged to what extent (to a considerable degree, to a certain degree, or not at all) the photograph corresponded to each of the following eight emotions: happiness, anger, sadness, shame, guilt, contempt, surprise, and fear. The most frequent answer, what the majority of the respondents regard as correct, is counted as the correct response. This consensus scoring has been shown to be the most effective, and provides a solution to the problem of what constitutes the correct answer (Mayer et al., 2002). The total score used in the analyses was calculated by adding all scores on the 32 items, and dividing by the number of photographs, and reflects to what extent the responses fits those of the norm for this sample.

\section{Procedure}

Participants volunteered by responding to flyers in the Department of Psychology. The flyers contained information with a brief description of the general purpose of the study and an email address which to send a message in case of interest. Individuals who emailed to express their interest in participating received an email with once again a brief description of the general purpose of the study, instructions of how to proceed, and links to two web surveys to fill out. Information about anonymity, voluntary participation, and data confidentiality was included in the description of the study. To make sure that a matching of the individual's answers on the two surveys would be possible later, participants received a personal id-number in their email that should be filled out in each of the questionnaires. It took the students about 20 minutes to fulfill the two questionnaires and they received course credit for their involvement in the study.

\section{Results}

The impression management scale correlated significantly with the self-report EI score $(r=.392, p<.001)$ and with the sociability score $(r=.350, p<.002)$. Further analyses were conducted with impression management partialled out. Mean values, standard deviations and internal consistency analyses were carried out for each of the ASQ dimensions, as well as performance EI, self-reported EI, and sociability. Results are shown in table 1.

Mean values on the ASQ subscales closely matched the Swedish norms (Håkansson \& Tengström, 1997) as did both EI scales and sociability scale mean values (Sjöberg, 2010) which means our sample seem to be representative of the target population. Because of the skewness in data, analyses of gender differences will not be conducted in the study. 
Table 1. Mean values, standard deviations and reliability measures on the five ASQ dimensions, performance EI, self-reported EI, and sociability.

\begin{tabular}{llll}
\hline & M & SD & Alpha \\
ASQ & & & \\
Confidence with self and others & 4.17 & .69 & .73 \\
Discomfort with closeness & 3.41 & .88 & .83 \\
Relationships as secondary & 2.13 & .69 & .77 \\
Preoccupation with relationships & 3.49 & .73 & .70 \\
Need for approval & 3.34 & .78 & .69 \\
Emotional Intelligence & & & \\
Performance EI & & & \\
Self-reported EI & 5.25 & 1.59 & .77 \\
& 3.38 & .46 & .74 \\
Sociability & & & \\
\hline
\end{tabular}

Performance EI showed no significant correlation with neither self-reported EI ( $r=-$ $.16)$, nor sociability $(r=.01)$. There was a strong significant correlation between selfreported EI and sociability $(r=.63, p<.0005)$.

In order to map the properties of the ASQ, Pearson product moment correlations between the ASQ subscales were performed. The results showed to a large extent expected results, consistent with earlier research and supporting the structure of the construct (Feeney et al, 1994; Tengström \& Håkansson, 1997). Confidence in self and others was negatively correlated with discomfort $(r=-.60, p<.0005)$, need for approval $(r=-.48, p<.0005)$ and with preoccupation with relationships $(r=-.37, p=.001)$ and negatively, but not significant, with relationships as secondary ( $r=-.21$, ns). Discomfort was positively correlated with need for approval $(r=.45, p<.0005)$, relationships as secondary $(r=.42, p<.0005)$ and preoccupation with relationships $(r=.25, p=.03)$. Need for approval was significantly correlated with preoccupation with relationships $(r$ $=.50, p<.0005)$ but not with relationships as secondary $(r=.07, \mathrm{~ns})$. There was no significant correlation between preoccupation with relationships and relationships as secondary $(r=-.06, \mathrm{~ns})$.

Correlations between the ASQ and EI scales were performed. Table 2 shows that there are no significant correlations between the ASQ dimensions and performance EI. However, all of the ASQ dimensions did correlate significantly with self-reported EI. Confidence correlated positively, the higher confidence in self and others the higher self-reported EI. The four insecure dimensions were negatively related to self-reported EI; the stronger feeling of discomfort with others, the more relationships are viewed as secondary, the higher need for approval and the more preoccupied with relationships, the lower self-reported EI. The confidence subscale did show a positive correlation with sociability, individuals who reported high confidence in self and others also reported high sociability. In addition, persons who reported high discomfort with closeness and high need for approval also reported low sociability. 
Table 2. Correlations between attachment dimensions and performance EI, self-report EI and sociability.

Confidence in self and others Performance EI

Discomfort w/closeness $-.05$

Relationships as secondary

Preoccupation w/ relationships

.09

Need for approval

.13

\begin{tabular}{cc} 
Self-report EI & Sociability \\
$.38^{* *}$ & $.48^{* * *}$ \\
$-.28^{*}$ & $-.29 *$ \\
$-.27 *$ & -.17 \\
$-.25^{*}$ & -.16 \\
$-.23^{*}$ & $-.29 *$ \\
\hline
\end{tabular}

$* \mathrm{p}<.05, * * \mathrm{p}<.01, * * * \mathrm{p}<.001$

The five ASQ dimensions were correlated, hence share variability (Feeney et al., 1994). To determine how the dimensions as a model explain variability in EI and sociability and which particular dimensions of attachment would predict EI and sociability beyond the influence of the others, multiple regression analyses were performed on self-report EI and sociability, with the five ASQ dimensions as predictors (table 3).

Table 3. Summary of results from multiple regression analysis with score on self-report EI and sociability as criterion variables and ASQ dimensions as predictors.

\begin{tabular}{|c|c|c|}
\hline & $\underline{\text { Self-report EI }}$ & $\underline{\text { Sociability }}$ \\
\hline & $\mathrm{R}_{\text {adj }}^{2} \beta$ & $\mathrm{R}^{2}$ adj $\quad \beta$ \\
\hline Step 1 & $143 * *$ & $.187 * *$ \\
\hline Confidence in self and others & .28 & $.45^{* *}$ \\
\hline Discomfort w/ closeness & .03 & .06 \\
\hline Relationships as secondary & -.23 & -.09 \\
\hline Preoccupation w/ relationships & -.16 & .04 \\
\hline Need for approval & -.01 & -.11 \\
\hline
\end{tabular}

The results of the regression analysis, using the enter method, indicate that the attachment dimensions have a significant effect on self-report $\mathrm{EI}\left(\mathrm{F}_{5,69}=2.93, p=.008\right)$. The ASQ dimensions accounted for $14 \%$ of the variance. However, none of the ASQ scales showed significant beta weights thus not accounting for unique variance. The regression analysis of attachment dimensions on sociability revealed a pattern of results similar to those of self-report EI with a total variance of $19 \%$ accounted for by the model $\left(\mathrm{F}_{5,69}=4.40, p=.002\right)$. With all other variables held constant, sociability was significantly related to confidence in self and others $(\mathrm{t}=3.26, p=.002)$.

\section{Discussion}

The purpose of the present study was to investigate the impact of attachment dimensions on EI and sociability. The current data did not offer conclusive evidence for the impact of attachment on EI, but suggests that secure attachment predicts sociability.

The predictions were not confirmed regarding the relationship between attachment dimension and EI measured as ability with a performance test. There were no correlations between any of the five dimensions and performance EI. Inconsistent with 
one previous study (Magai et al., 1995) and consistent with another (Kafetsios, 2004) this study did not find positive correlations between confidence in self and others (secure attachment) and the ability to decode facial expressions. However, research on attachment and ability EI has been sparse and inconsistent; Magai et al., (1995) found a negative relationship between avoidant attachment and decoding facial expression while Kafetsios (2004) only found a negative correlation with preoccupied attachment.

The lack of relationship in this sample might be due to several reasons. Attachment is established in the contact between child and caregiver and if EI is an ability we are born with, a cognitive ability (as according to Christiansen et al., 2010) not affected by the attachment, this would suggest that there is no relationship between the two constructs because they depend on totally different things. Being able to detect/judge emotions in faces is not related to your attachment to others, it is an ability that you are born with and either possess or do not posses, regardless of you attachment.

All of the attachment dimensions were related to self-report EI in an expected way, confidence in self and others positively and the four dimensions reflecting insecure attachment negatively. Together as a model, they predicted EI. However, none of the dimensions made significant contribution to the multiple regression, their correlation with self-reported EI is suggested to be due to other variables.

Thompson et al. (1995) showed that children with secure attachment are more emotionally competent, and the findings in the present study might suggest that even though attachment is important for emotional understanding during childhood, the effect of it declines during ontogeny. Emotion regulation is developed in childhood, in the child's attachment relation and attachment predicts the child's emotional ability in childhood but adult attachment does not predict current self-reported EI. Studies have showed that our attachment orientations can change over time (e.g. Sroufe et al., 1999; Zimmerman et al., 1997), and this might suggest that a securely attached child will understand emotions to a higher degree than an insecurely attached child, but events during life may be the reason this prediction disappears. As the cognitive part of the emotion regulation develops, the impact of attachment seems to disappear. Both attachment and EI have insecure developmental patterns during ontogeny; if, how and why they change is not ensured and longitudinal studies are important to clarify their progress.

Confidence in self and others was positively correlated with sociability and accounted for unique variance in the regression analysis. As expected, the insecure dimensions were negatively related to sociability; discomfort with others and need for approval achieved significance. These results indicate that confidence in self and others predicts sociability, lending support to the notion that securely attached individuals provide higher quality care to others (Mikulincer \& Shaver, 2005), and are more socially skilled (DiTommaso et al., 2003). The result is also in line with Kafetsios and Nezlek's (2002) study where securely attached people had better interactions in the sense of the relations being more intimate and positive. The results may depend on securely attached individuals being able to show a wider range of emotions and react to emotional events with adaptation. This helps them maintain and enhance good relationships. The fact that securely attached individuals view others as available and responsive would make them more likely to engage in direct and coherent communication, as well as acquire new and 
manage old relationships in a good way. Social skills depend to a high degree on your confidence, on you belief that you are able to handle it, that others will like you, and that others are worthy your love.

Self-reported EI and sociability correlated strongly in our sample, supporting the notion that the two constructs are highly related (Argyle \& Lu, 1990; Ciarrochi et al., 2000; Rubin, 1999). The predictive value of attachment security on sociability but not EI is interesting. Since emotion information can be processed in different ways, affective or cognitive, the findings may depend on the fact that attachment orientations affect people's ability to maintain relationships. Affective expression increasingly becomes under voluntary control as self-monitoring and cognitive abilities develop and these interact with socialization. With a better capacity to hold long-term plans and understand symbolic logic, kids learn to control affect and there are two reasons for this, to motivate pursuit of goals, and conform to social expectations (Fuendeling, 1998). Affective responses are being shaped by parental responses, and there is an increasing interdependence of affect and cognition as the child matures. Working models are expectations that are internalized; they may not predict emotional and social outcomes later in life if the models of self change over time. Dependent on children's cognitive and emotional understanding of the surroundings, specific experiences may have a bigger impact than others on the adult's working models. More research in this field, for example on the development of relation between memory and social cognition, is of crucial importance.

No correlation between performance and self-report EI was found in the present study which supports the two-factor model where performance EI is more related to cognitive ability and self-report EI to personality (Christiansen et al., 2010). This might also explain why there is no correlation between attachment and ability EI. The result highlights the confusion that surrounds the construct of EI.

Even if studying attachment as dimensions is more advantageous than using categories, is it important to remember that gathering data with self-reports is always associated with difficulties. When it comes to attachment there might be a tendency of people having specific relationships close in mind that affects how they perceive all relationships on a global level. The individual's overall judgments on the attachment related statements might be affected by these specific, and close in time, relationships.

Furthermore, the UPP test only assesses one type of ability EI with the performance test; perception of emotions. Future studies of the ASQ dimensions on all of Mayer and Salovey's (1997) components of EI will provide more information on the constructs because this conceptualization highlights the interactions of cognition and affect and emotion information processing might be a key variable.

Because of the nature of this study, causal interpretations must be cautious. There are reasons to believe that the direction of the links between attachment and sociability are in fact bi-directional. Persons with high self-reported sociability are more likely to establish and maintain good relationships. These healthy relationships most likely affect the feeling of confidence in self and others. Being in good and healthy relationships help people develop and increase their emotional and social abilities. Especially sociability is interesting since infants show differences in social behavior (Flanagan, 1999), which might affect how responsive their environment will be towards them and 
to what extent they will form attachment bonds. The sociability of the child might affect not only the quality of the bonds, but also the quantity.

The sample size and he homogeneity of the sample (Swedish university students of whom $79 \%$ are women) should be taken into consideration when generalizing the findings of this study.

One of the advantages of the present study is the use of self-report as well as performance-based measures of EI. Since researchers still have not come to conclusion about what EI is and how it should be measured, and both approaches has shown either predictive (self-reports) or theoretical (performance-based measures) validity, it is of interest to include both. Another advantage is that the UPP test includes correction for impression management.

The study provides important addition to the research on the relationship between attachment, EI, and sociability thanks to its dimension approach instead of attachment styles. Although longitudinal studies of the predictive relation between attachment, EI and sociability are needed since interpreting associations between concurrent variables gives no information about causal relations, identifying relationships between emotional and social correlates concurrent with attachment dimensions helps clarify the significance of the constructs.

Even though several studies have examined the relations between attachment and emotions, research on the relationship between attachment orientations and overall EI is sparse. A more integrative approach is needed to create a framework for understanding our behavior. The present study is a first attempt to study the relationship between attachment dimensions and EI measured as ability with performance test as well as with self-reports. Attachment, EI and sociability are all complex constructs, and much research will be needed to establish the relationships between them.

\section{References}

Ainsworth, M. D. S. (1967). Infancy in Uganda. Baltimore: Johns Hopkins University Press.

Ainsworth, M. D. S., Blehar, M. C., Waters, E., \& Wall, S. (1978). Patterns of attachment: Assessed in the strange situation and at home. Hillsdale, NJ: Erlbaum.

Argyle, M., \& Lu, L., (1990). Happiness and social skills. Personality and Individual Differences, 11, $1255-1261$.

Bar-On, R. (1997). Bar-On Emotional Quotient Inventory: technical manual. Toronto, ON: Multi-Health Systems.

Bar-On, R. (2006). The Bar-On model of emotional-social intelligence (ESI). Psicothema, 18, 13-25.

Bartholomew, K. (1990). Avoidance of intimacy: An attachment perspective. Journal of Social and Personal Relationships, 7, 147-178.

Bartholomew, K., \& Horowitz, L. M. (1991). Attachment styles among young adults: A test of a four category model. Journal of Personality and Social Psychology, 61, 226-244. 
Bookwala, J., \& Zdaniuk, B. (1998). Adult attachment styles and aggressive behavior within dating relationships. Journal of Social and Personal Relationships, 15, 175-190.

Bowlby, J. (1969). Disruption of affectional bonds and its effects on behavior. Canada's Mental Health Supplement, 59, 12.

Bowlby, J. (1969/1982). Attachment and loss: Vol. 1. Attachment (2 $2^{\text {nd }}$ ed.). New York, NY: Basic Books $\left(1^{\text {st }}\right.$ ed. Published in 1969).

Bowlby, J. (1973). Attachment and loss: Vol. 2. Separation: Anxiety and anger. New York, NY: Basic Books.

Brackett, M. A., Rivers, S. E., Shiffman, S., Lerner, N., \& Salovey, P. (2006). Relating emotional abilities to social functioning: A comparison of self-report and performance measures of emotional intelligence. Journal of Personality and Social Psychology, 91, 780-795.

Brennan K. A., \& Shaver, P. R. (1995). Dimensions of Adult Attachment, Affect Regulation, and Romantic Relationship Functioning. Personality and Social Psychology Bulletin, 21, 267-283.

Bretherton, I., \& Munholland, K. A. (1999). Internal working models in attachment relationships: A construct revisited. In J. Cassidy \& P. R. Shaver (Eds), Handbook of attachment: Theory, research, and clinical applications (pp. 89-111). New York: Guilford Press.

Cassidy, J. (1994). Emotion regulation: influences of attachment relationships. Monographs of the Society for Research in Child Development, 59, 228-283.

Christiansen, N. D., Janovics, J. E., \& Siers B. P. (2010). Emotional Intelligence in Selection Contexts: Measurement method, criterion-related validity, and vulnerability to response distortion. International Journal of Selection and Assessment, 18, 87-101.

Ciarrochi, J. V., Chan, A. Y. C., \& Caputi, P. (2000). A critical evaluation of the emotional intelligence construct. Personality and Individual Differences, 28, 539-561.

Collins, N. L. (1996). Working models of attachment: Implications for explanation, emotion and behaviour. Journal of Personality and Social Psychology, 71, 810-832.

Collins, N., \& Read, S. J. (1994). Cognitive representations of attachment: The structure and function of working models. In D. Perlman \& K. Bartholomew (Eds.), Advances in personal relationships (Vol. 5, pp. 53-90). London: Jessica Kingsley.

Cooper M. L., Shaver P. R., \& Collins N. L. Attachment styles, emotion regulation, and adjustment in adolescence. Journal of Personality and Social Psychology, 74, 1380-1397.

Darwin, C. (1872). The expression of emotions in man and animals. London: John Murray.

DiTomasso, E., Brannen-McNulty, C., Ross, L., \& Burgess, M. (2003). Attachment styles, social skills and loneliness in young adults. Personality and Individual Differences, 35, 303-312.

Feeney, J. A,, \& Noller, P. (1991). Attachment style and verbal descriptions of romantic partners. Journal of Social and Personal Relationships, 8, 187-215.

Feeney, J. A., Noller, P., \& Hanrahan, M. (1994). Assessing adult attachment. In M. B. Sperling \& W. H. Berman (Eds.), Attachment in adults: Clinical and developmental perspectives (pp. 122-158). New York: Guilford.

Fischer, K. W. Shaver. R., \& Carnochan, P. (1990). How emotions develop and how they organise development. Cognition and Emotion, 4, 81-127. 
Flanagan, C. (1999). Early socialisation: Sociability and attachment. London: Routledge.

Fuendeling, J. M. (1998). Affect regulation as a stylistic process within adult attachment. Journal of Social and Personal Relationships, 15, 291-322.

Goleman, D. (1995). Emotional intelligence. New York: Bantam Books.

Griffin, D., \& Bartholomew, K. (1994). Models of the self and other: fundamental dimensions underlying measures of adult attachment. Journal of Personality and Social Psychology, 67, 430-445.

Hamarta, E., Deniz, M. E., \& Saltali, N. (2009). Educational sciences: Theory \& Practice, 9, 213-229.

Hazan, C., \& Shaver, P. (1987). Romantic love conceptualised as an attachment process. Journal of Personality and Social Psychology, 52, 511-524.

Håkansson, A., \& Tengström, A. (1997). Attachment Style Questionnaire: Manual for the Swedish version. Unpublished master's thesis, Umeå University.

Joseph, D. L., \& Newman, D. A. (2010). Emotional Intelligence: An Integrative Meta-Analysis and Cascading Model. Journal of Applied Psychology, 95, 54-78.

Kafetsios, K. (2004). Attachment and emotional intelligence abilities across the life course. Personality and Individual Differences, 37, 129-145.

Kafetsios K., \& Nezlek, J. B. (2002) Attachment styles in everyday social interaction. European Journal of Social Psychology, 32, 719-735.

Kobak, R. R., \& Sceery, A. (1988). Attachment in late adolescence. Child Development, 59, 135-146.

Laible, D. (2007). Attachment with parents and peers in late adolescence: Links with emotional competence and social behavior. Personality and Individual Differences, 43, 1185-1197.

Lopes, P. N., Salovey, P., \& Straus, R. (2003). Emotional intelligence, personality, and the perceived quality of social relationships. Personality and Individual Differences, 35, 641-658.

Magai, C., Distel, N., \& Liker, R. (1995). Emotion socialisation, attachment and patterns of adult emotional traits. Cognition and Emotion, 9, 461-481.

Main, M., \& Cassidy, J. (1988). Categories of response to reunion with the parent at age 6: Predictable from infant attachment classifications and stable over a 1-month period. Developmental Psychology, 24, 415-426.

Mayer, J., \& Salovey, P. (1997). What is emotional intelligence? In P. Salovey \& D. Sluyter (Eds.), Emotional development and emotional intelligence (pp. 3-31). New York: Basic Books.

Mayer, J. D., Salovey, P., \& Caruso, D. R. (2000). Selecting a measure of emotional intelligence: the case for ability scales. In R. Bar-On \& J. D. A. Parker (Eds.), The handbook of emotional intelligence. San Francisco: Jossey-Bass.

Peck, S. D. (2003). Measuring sensitivity moment-by-moment: A microanalytic look at the transmission of attachment. Attachment and Human Development, 5, 38-63.

Petrides, K. V., \& Furnham, A. (2000) On the dimensional structure of emotional intelligence, Personality and Individual Differences, 29, 313-320.

Rubin, M. M. (1999). Emotional intelligence and its role in mitigating aggression: A correlation study of the relationships between emotional intelligence and aggression in urban adolescents. Unpublished manuscript, Immaculata College, Immaculata, PA. 
Salovey, J., \& Mayer, J.D. (1990). Emotional intelligence. Imagination, Cognition, and Personality, 9, $185-211$.

Schachter, S. (1951). Deviation, rejection, and communication. Journal of Abnormal and Social Psychology, 46, 90-207.

Shaver, P. R., Collins, N., \& Clark, K. L. (1996). Attachment styles and internal working models of self and relationship partners. In G. J. O. Fletcher, \& J. Fitness (Eds.), Knowledge structures in close relationships: A social psychological approach (pp. 25-61). Mahwah, NJ: Lawrence Erlbaum.

Simpson, J. A. (1990). Influence of attachment styles on romantic relationships. Journal of Personality and Social Psychology, 59, 971-980.

Simpson, J. A., Rholes, W. S., \& Nelligan, J. S. (1992). Support Seeking and Support Giving within Couples in an Anxiety-Provoking Situation: The Role of Attachment Styles. Journal of Personality and Social Psychology, 62, 434-446.

Sjöberg, L. (2001). Emotional intelligence: A psychometric analysis. European Psychologist, 6, 79-95.

Sjöberg, L. (2008). Beyond Big Five: Construction and validation of a personality test. (SSE/EFI Working Paper Series in Business Administration No. 2008:7). Stockholm: Stockholm School of Economics.

Sjöberg, L. (2009). The UPP test: Correction for impression management. Stockholm: Psykologisk Metod AB.

Sjöberg, L. (2010). The UPP-test. Understanding personal potential. Manual. Stockholm: Psykologisk Metod AB.

Sroufe, L. A., Carlson, E. A., Levy, A. K., \& Egeland, B. (1999). Implications of attachment theory on developmental psychopathology. Development and Psychopathology, 11, 1-13.

Stein, H., Koontz, A. D., Fonagy, P., Allen, J.G., Fultz, J., Brethour, J. R., et al. (2002). Adult attachment: What are the underlying dimensions? Psychology and Psychotherapy: Theory, Research and Practice, 75, $77-91$.

Thompson, R. A. (1999). Early attachment and later development. In J. Cassidy \& P. R. Shaver (Eds.), Handbook of attachment: Theory, research, and clinical applications (pp. 265-286). New York: Guilford Press.

Thompson, R. A., Flood, M., \& Lundquist, L. (1995). Emotional regulation: Its relations to attachment and developmental psychopathology. In D. Cicchetti \& S. Toth (Eds.), Emotion, cognition, and representation (pp. 261-299). Rochester, NY: University of Rochester Press.

Thompson, R. A., \& Lamb, M. E. (1983). Security of attachment and stranger sociability in infancy. Developmental Psychology, 19, 184-191.

Zimmermann, P. (1999). Structure and functions of internal working models of attachment and their role for emotion regulation. Attachment \& Human Development, 1, 291-306.

Zimmermann, P., Fremmer-Bombik, E., Spangler, G., \& Grossman, K. E. (1997). Attachment in adolescence: A longitudinal perspective. In W. Koops, J. B. Hoeksma, \& D. C. van den Boom (Eds.), Development of interaction and attachment (pp. 281-292). Amsterdam: Elsevier. 